\title{
In vivo length change of ligaments of normal knees during dynamic high flexion
}

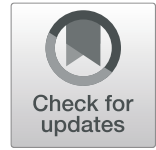

Kenichi Kono ${ }^{1,2}$, Shoji Konda ${ }^{2}$, Takaharu Yamazaki ${ }^{3}$, Sakae Tanaka', Kazuomi Sugamoto ${ }^{2}$ and Tetsuya Tomita ${ }^{2 *}$ (D)

\begin{abstract}
Background: Few studies compared the length change of ligaments of normal knees during dynamic activities of daily living. The aim of this study was to investigate in vivo length change of ligaments of the normal knees during high flexion.

Methods: Eight normal knees were investigated. Each volunteer performed squatting, kneeling, and cross-leg motions. Each sequential motion was performed under fluoroscopic surveillance in the sagittal plane. The femoral, tibial, and fibular attachment areas of the anterior cruciate ligament ( $A C L)$, posterior cruciate ligament $(P C L)$, deep medial collateral ligament ( $\mathrm{dMCL}$ ), superficial medial collateral ligament (sMCL), and lateral collateral ligament $(\mathrm{LCL})$ were determined according to osseous landmarks. After 2D/3D registration, the direct distance from the femoral attachment to the tibial or fibular attachment was measured as the ligament length.
\end{abstract}

Results: From $20^{\circ}$ to $90^{\circ}$ with flexion, the $\mathrm{ACL}$ was significantly shorter during cross-leg motion than during squatting. For the $P C L, d M C L, S M C L$, and $L C L$, there were no significant differences among the 3 motions.

Conclusion: The ACL was shorter during cross-leg motion than during squatting in mid-flexion. This suggests that the $\mathrm{ACL}$ is looser during cross-leg motion than during squatting. On the other hand, the length change of the $\mathrm{PCL}$, $M C L$, and $L C L$ did not change even though the high flexion motions were different.

Keywords: Length change of ligaments, Kinematics, Squatting, Kneeling, Cross-leg

\section{Background}

Soft tissue balance such as ligament balance is one of the most important factors for successful total knee arthroplasty (TKA). In addition, ligament-retained TKA has increased worldwide. Therefore, surgeons now take more interest in the ligament balance of the knee. Many previous studies reported length change to the ligaments of normal knees [1-10]. However, some studies examined the in vitro condition $[1,5,7]$. Regarding in vivo studies, they examined static motions or simple active motions $[2-4,6,8,10,11]$ such as leg flexion and extension. Several studies evaluated the length change of ligaments of normal knees during dynamic activities of daily living [9, 12-14]. Kernkamp

\footnotetext{
*Correspondence: tomita@ort.med.osaka-u.ac.jp

${ }^{2}$ Department of Orthopaedic Biomaterial Science, Osaka University Graduate School of Medicine, 2-2 Yamada-oka, Suita, Osaka 565-0871, Japan

Full list of author information is available at the end of the article
}

et al. measured the in vivo anterolateral ligament length change in healthy knees during step-up and sit-to-stand motions under dynamic conditions [13]. Taylor et al. used a combination of magnetic resonance imaging (MRI), Motion Capture, and dual fluoroscopy to characterize relative strain in an anterior cruciate ligament (ACL) during both stance and swing phases of normal level walking [12]. Liu et al. measured the in-vivo length patterns of the deep medial collateral ligament (dMCL) and superficial medial collateral ligament (sMCL) during walking using dual fluoroscopy [9]. Rao et al. investigated the length changes of ACL and posterior cruciate ligament (PCL) during a single-legged lunge [14]. However, few studies directly compared the length change of ligaments of normal knees during dynamic high flexion activities of daily living.

Especially in Asia and the middle-east, people commonly bend their knees deeply in daily living, like sitting

(c) The Author(s). 2020 Open Access This article is licensed under a Creative Commons Attribution 4.0 International License, which permits use, sharing, adaptation, distribution and reproduction in any medium or format, as long as you give appropriate credit to the original author(s) and the source, provide a link to the Creative Commons licence, and indicate if changes were made. The images or other third party material in this article are included in the article's Creative Commons licence, unless indicated otherwise in a credit line to the material. If material is not included in the article's Creative Commons licence and your intended use is not permitted by statutory regulation or exceeds the permitted use, you will need to obtain permission directly from the copyright holder. To view a copy of this licence, visit http://creativecommons.org/licenses/by/4.0/. The Creative Commons Public Domain Dedication waiver (http://creativecommons.org/publicdomain/zero/1.0/) applies to the data made available in this article, unless otherwise stated in a credit line to the data. 
on the floor and praying. In Western countries, many people perform a squatting position while they play sports. In addition, several studies have demonstrated that the in vivo kinematics of normal knees during high-flexion activities are significantly different [15-17]. Therefore, it is important to investigate the length change during high-flexion motions all over the world. Furthermore, several reports have demonstrated that patients' satisfaction with TKA has been greater with a medial pivot pattern, such as in normal knees [18, 19]. Therefore, we thought that it was necessary to evaluate the length change of ligaments of normal knees during high flexion to further increase patients' satisfaction after ligamentretained TKA.

The aim of this study was to investigate in vivo length change of ligaments of normal knees during dynamic high-flexion activities. The hypothesis of this study was that the length change of ligaments of normal knees was different depending on the high flexion activities of daily living.

\section{Methods}

A total of 8 normal knees (4 Japanese healthy male volunteers) were investigated. At the time of the investigation, their mean age was $41.8 \pm 6.5$ years, mean height was $170.3 \pm 5.9 \mathrm{~cm}$, and mean weight was $68.5 \pm 9.7 \mathrm{~kg}$. This study was approved by the ethics committee, and all of the volunteers provided written, informed consent prior to participation.

Each volunteer was asked to perform squatting, kneeling, and sitting cross-legged (cross-leg) motions. The activities were performed under fluoroscopic surveillance in the sagittal plane (Fig. 1). The kneeling motion was measured from $100^{\circ}$ to $150^{\circ}$ with flexion. Sequential knee flexion was recorded as digital X-ray images $(1024 \times 1024 \times 12 \mathrm{bits} /$ pixel, $7.5-\mathrm{Hz}$ serial spot images as a DICOM file) using a 17-in. flat panel detector system (C-vision Safire L; Shimadzu, Kyoto, Japan). On this system, acquired images were nondistorted and clear compared with the Image Intensifier system (Shimadzu). In addition, all images were processed by dynamic range compression, enabling edge-enhanced images. To estimate spatial position and orientation of the knee, a 2-dimensional/3-dimensional (2D/3D) registration technique was used $[20,21]$. This technique is based on a contour-based registration algorithm using single-view fluoroscopic images and 3D computer-aided design (CAD) models. Three-dimensional bone models were created from computed tomography (CT) and used as CAD models for subsequent $2 \mathrm{D} / 3 \mathrm{D}$ registration. The estimation accuracy of relative motion between 3D bone models was $\leq 1^{\circ}$ in rotation and $\leq 1 \mathrm{~mm}$ in translation [22]. A local coordinate system at the bone model was produced according to previous studies [22].

We defined the femoral, tibial and fibular attachment areas of the ACL, PCL, dMCL, sMCL and lateral collateral ligament (LCL) according to the osseous landmark $[8,10,23-31]$. The accuracy of the attachment area is $0.7 \pm 0.1 \mathrm{~mm}$ [31]. The collateral ligaments were each evenly divided into 3 portions (anterior (a), middle (m), and posterior $(\mathrm{p}))[8,10]$. The direct distance from the femoral attachment to the tibial or fibular attachment was measured as the ligament length (L) using software (MATLAB, MathWorks, Natick, MA, USA). The ligament length at $0^{\circ}$ of knee flexion during squatting was defined as the reference ligament length ( $\mathrm{L}$ ref). The
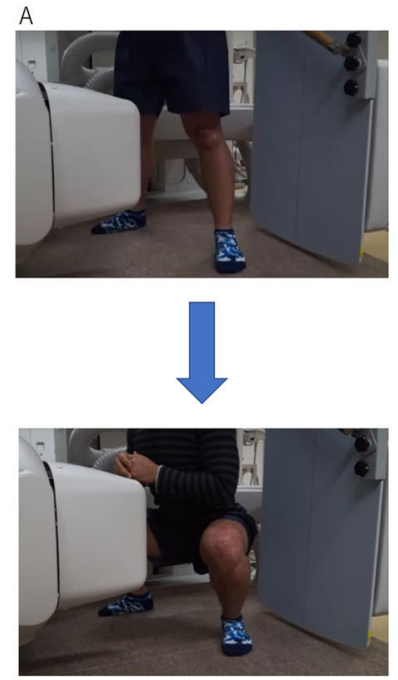

Fig. 1 The fluoroscopic analysis. a: Squatting. b: Kneeling. c: Sitting cross-legged
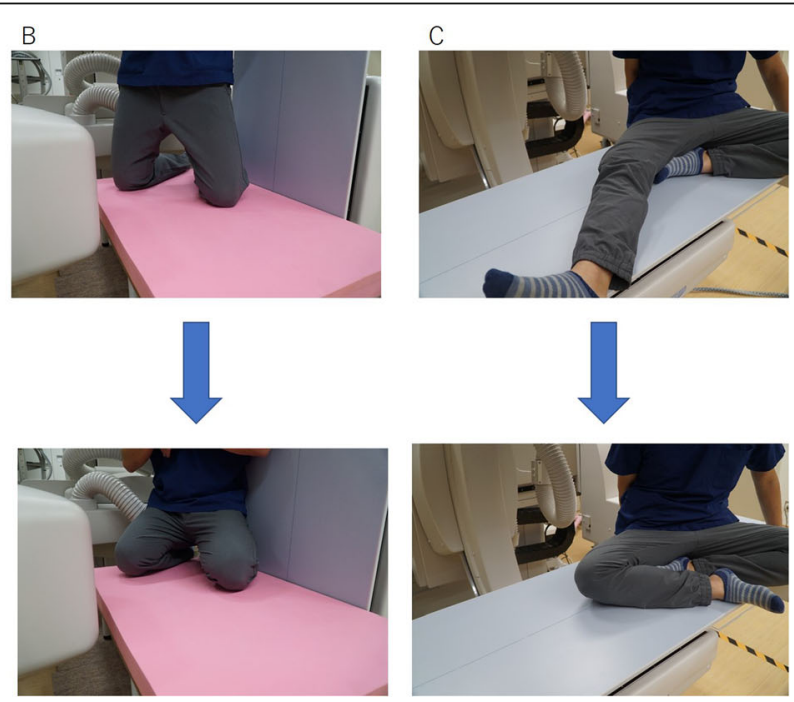
length change $(e)$ was calculated using an engineering strain formula (i.e. $e=(\mathrm{L}-\mathrm{L}$ ref $) / \mathrm{L}$ ref. $\times 100)$. Extension relative to the reference ligament length was denoted as positive, and shortening was denoted as negative (Video 1).

All data are expressed as means \pm standard deviations (SD). Two-way analysis of variance (ANOVA) and post hoc pair-wise comparison (Bonferroni correction) were used to analyze differences in the length change of each ligament among squatting, kneeling, and cross-leg motions. $p$-value $<.05$ were considered significant.

\section{Results}

$\mathrm{ACL}$

During squatting, the ACL shortened gradually up to an average of $-30.15 \% \pm 4.8 \%$ from $0^{\circ}$ to $120^{\circ}$ with knee flexion. From $120^{\circ}$ to $150^{\circ}$ with flexion, it extended an average of up to $-12.85 \% \pm 7.9 \%$. During kneeling, the ACL did not change significantly from $100^{\circ}$ to $130^{\circ}$ with flexion. From $130^{\circ}$ to $150^{\circ}$ with flexion, it extended from $-38.8 \% \pm 4.2 \%$ to $-31.9 \% \pm 6.3 \%$. During cross-leg motion, the ACL shortened gradually on average from $3.7 \% \pm 6.2 \%$ to $-36.9 \% \pm 4.3 \%$ from $0^{\circ}$ to $110^{\circ}$ with flexion. From $110^{\circ}$ to $150^{\circ}$ with flexion, it extended an average of up to $-24.9 \% \pm 6.3 \%$.

The length change of the ACL during squatting was smaller than that during cross-leg motion from $20^{\circ}$ to $90^{\circ}$ with flexion (Fig. 2).
PCL

The PCL extended gradually with flexion up to $37.6 \% \pm$ $10.3 \%$ during squatting, $43.5 \% \pm 18.8 \%$ during kneeling, and $37.9 \% \pm 21.6 \%$ during cross-leg motion. Among the 3 deep bending activities, there was no significant difference (Fig. 2).

\section{$\mathrm{MCL}$}

Regarding $\mathrm{dMCL}$, adMCL, and $\mathrm{mdMCL}$ extended from $0^{\circ}$ to $120^{\circ}$ (adMCL $42.6 \% \pm 21.4,45.5 \% \pm 20.2$, and $39.5 \% \pm$ $18.8 \%$ during squatting, kneeling, and cross-leg motion, respectively; mdMCL $28.9 \% \pm 21.0, \quad 30.0 \% \pm 19.0$, and $21.5 \% \pm 18.1 \%$ during squatting, kneeling, and cross-leg motion, respectively). From $120^{\circ}$ to $150^{\circ}$, adMCL shortened $3.7 \% \pm 19.3, \quad 3.1 \% \pm 4.7$, and $16.6 \% \pm 12.1 \%$, during squatting, kneeling, and cross-leg motion, respectively, and mdMCL shortened $5.95 \pm 18.1,2.0 \% \pm 4.6$, and $15.2 \% \pm$ $11.4 \%$ during squatting, kneeling, and cross-leg motion, respectively. Regarding SMCL, asMCL extended $10.1 \% \pm$ $7.2 \%$ during squatting, $9.5 \% \pm 7.1 \%$ during kneeling, and $9.2 \% \pm 7.9 \%$ during cross-leg motion from $0^{\circ}$ to $100^{\circ}$ with flexion. From $100^{\circ}$ to $150^{\circ}$, they shortened $5.6 \% \pm 8.1$, $5.1 \% \pm 2.6$ and $11.3 \% \pm 5.4 \%$ during squatting, kneeling, and cross-leg motion, respectively. There were no significant differences in msMCL, psMCL, and pdMCL.

Among the 3 deep bending activities, there were no significant differences in both $\mathrm{dMCL}$ and SMCL (Figs. 3 and 4).

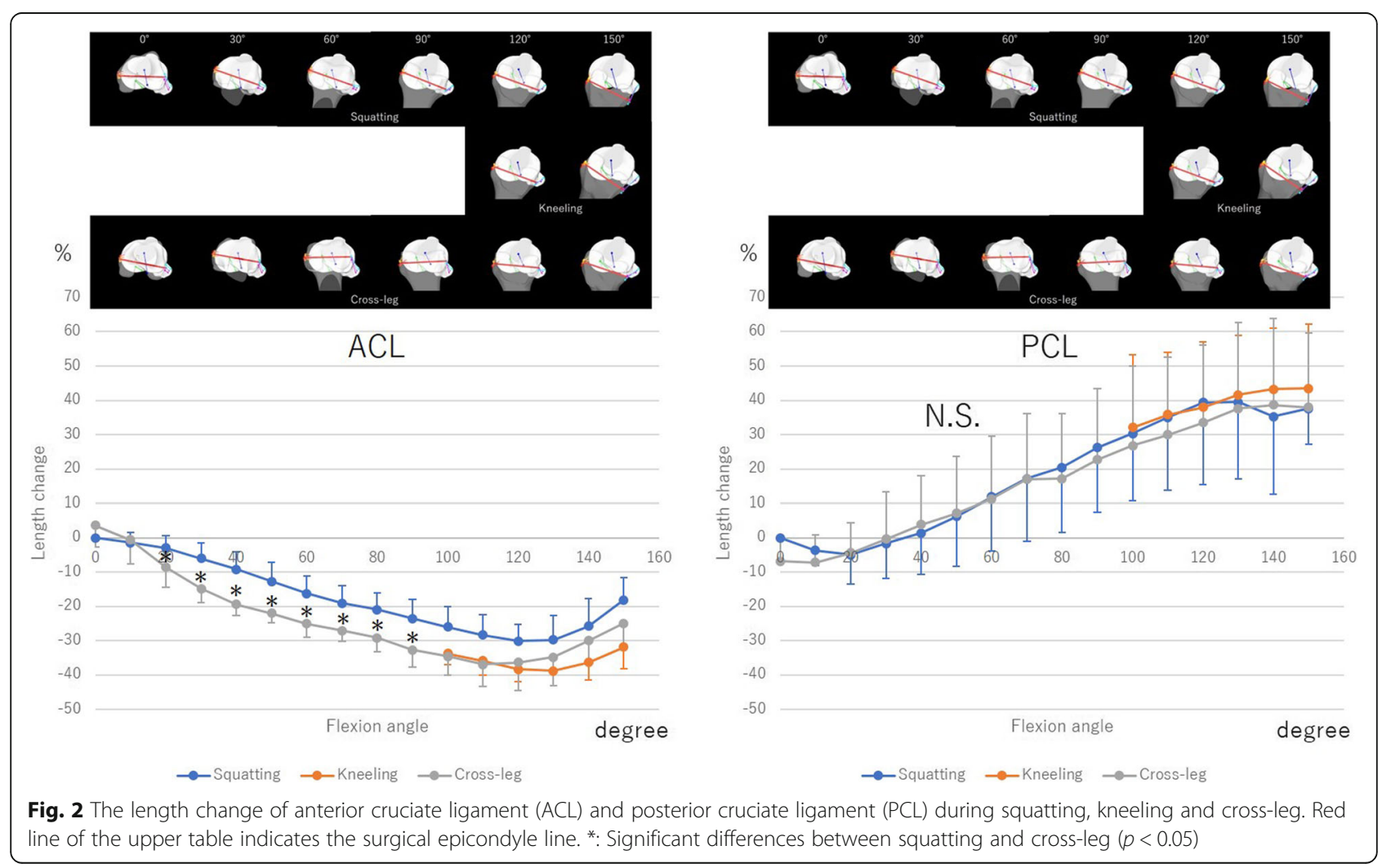




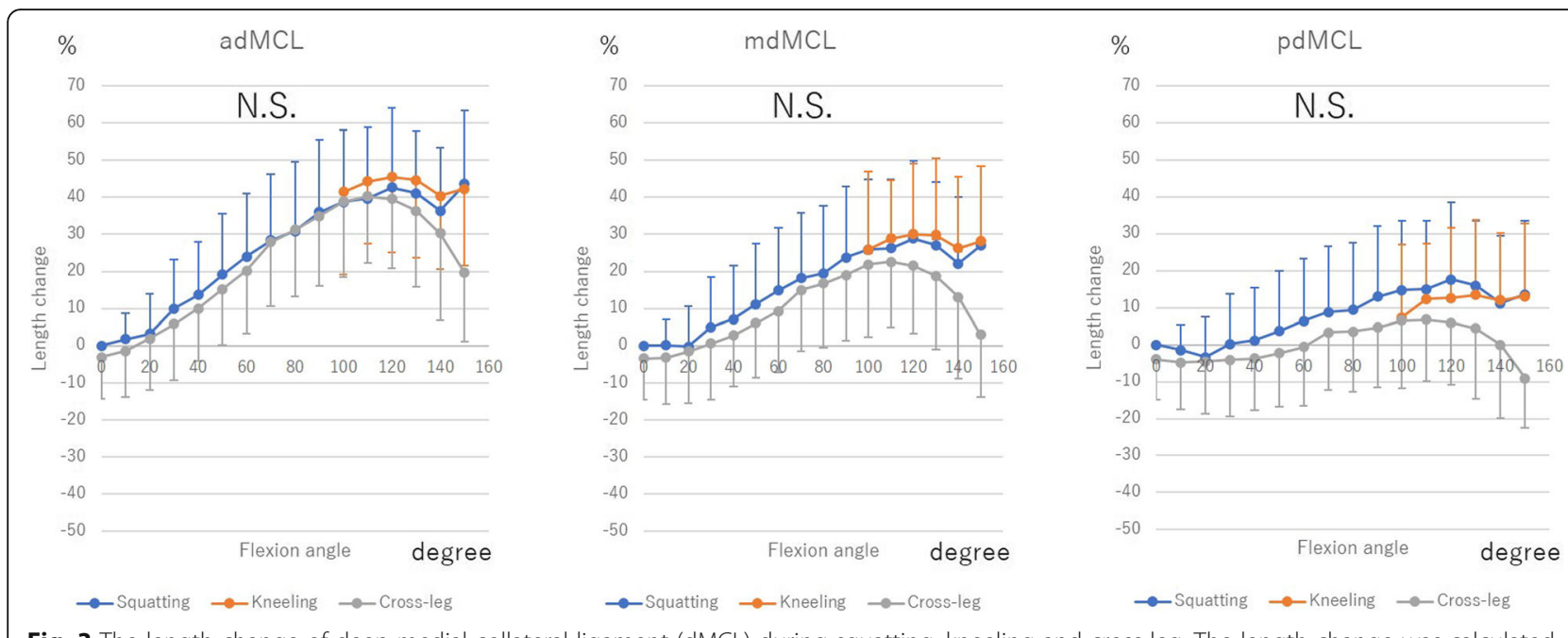

Fig. 3 The length change of deep medial collateral ligament (dMCL) during squatting, kneeling and cross-leg. The length change was calculated as the length change rate from the ligament length at $0^{\circ}$ of knee flexion during squatting. N.S.: Not significant

\section{LCL}

aLCL extended with flexion (up to $13.7 \% \pm 25.2 \%$ during squatting, $12.7 \% \pm 16.7 \%$ during kneeling, and $23.7 \% \pm$ $22.7 \%$ during cross-leg motion). On the other hand, there were no significant differences in $\mathrm{mLCL}$ and $\mathrm{pLCL}$.

Among the 3 deep bending activities, there were no significant differences (Fig. 5).

\section{Discussion}

A most important finding in this study was that the ACL was shorter during cross-leg motion than during squatting in mid-flexion. This fact suggested that the ACL is looser during cross-leg motion than during squatting. In other words, the ACL might be easy to affect by differences in flexion motions. Hence, ACLpreserved TKA might be able to reproduce the ACL length difference between squatting and cross-legged sitting. On the other hand, regarding length changes of the PCL, MCL, and LCL, there were no significant differences among the 3 motions. This suggested that the length changes of PCL, MCL, and LCL do not change even though the high-flexion motions are different. In addition, the ACL might be the most easily affected ligament of the knee in mid-flexion. The previous study demonstrated that the effect of coronal plane knee motion on cruciate ligament was larger than that of collateral ligament [32]. Additionally, ACL during Closed-Kinetic-Chain activities largely elongated, while that during Open-Kinetic-Chain activities slightly elongated [33]. Therefore, the ACLs have changed in crosslegged motion. In high flexion, the length change of the ACL was also not significantly different among the 3

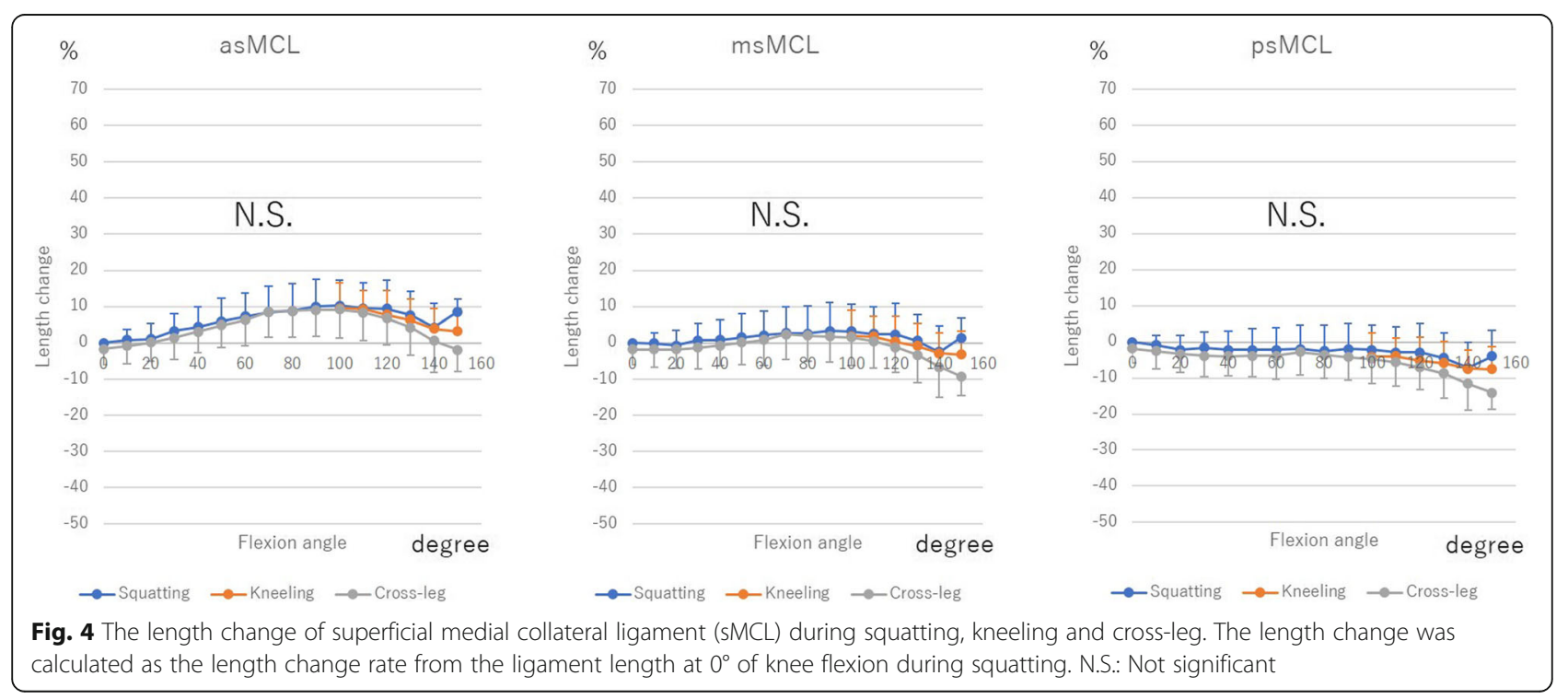



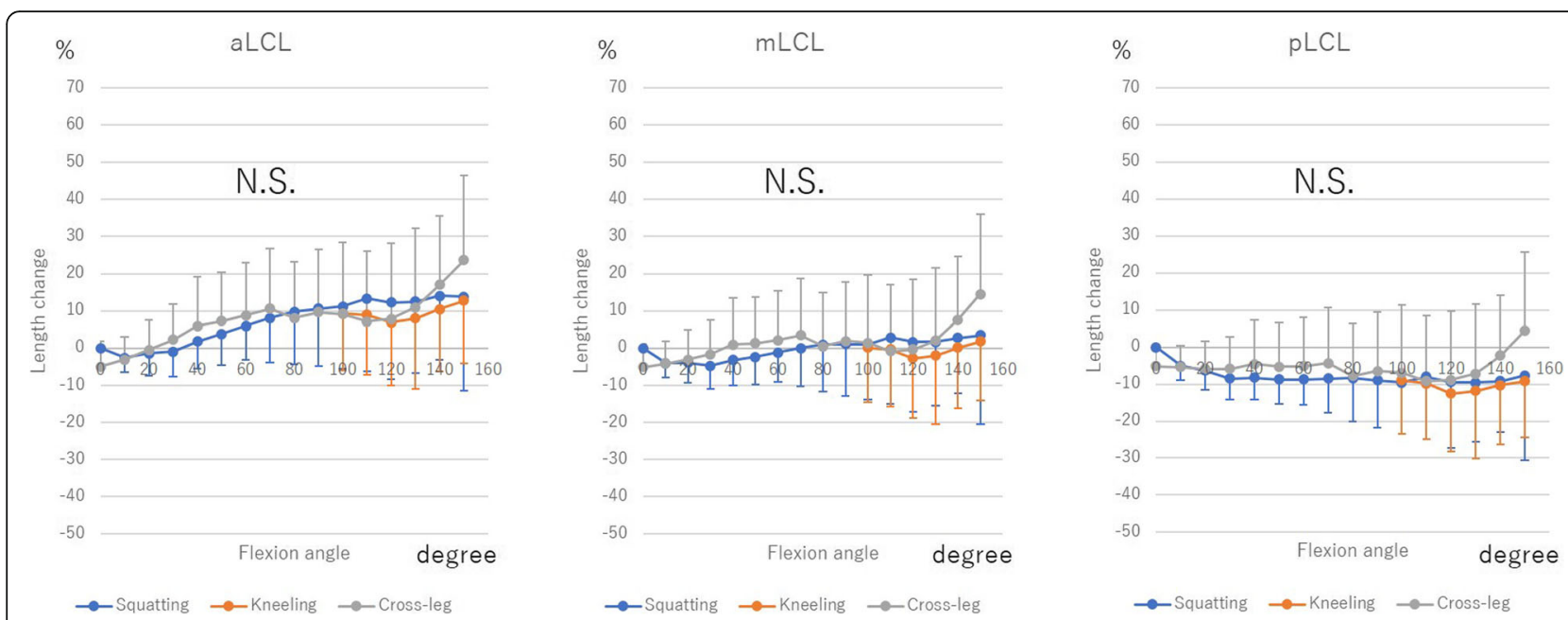

Fig. 5 The length change of lateral collateral ligament $(L C L)$ during squatting, kneeling and cross-leg. The length change was calculated as the length change rate from the ligament length at $0^{\circ}$ of knee flexion during squatting. N.S.: Not significant

motions. This suggested that any length changes of the ligaments do not change even though the flexion motions are different in high flexion. Therefore, regarding the ligament balance in bi-cruciate retaining TKA, the difference between the three activities might be low in high flexion.

From early flexion to mid-flexion, the ACL shortened with flexion. On the other hand, it extended slightly during high flexion. These tendencies were similar among the 3 motions. Additionally, the length change pattern with flexion was similar to that seen in previous in vivo studies using transducers $[2,3]$. However, the length change of previous studies was less than $10 \%$, while the length changes in the present study were more than $30 \%$. Many factors such as ethnicity, gender, age, body mass index, or method of analysis contribute to the difference. Especially the method of analysis, the previous studies were analyzed from $0^{\circ}$ to $90^{\circ}$ of flexion. While this study was evaluated from $0^{\circ}$ to $150^{\circ}$ of flexion. Moreover, another previous study that evaluated the ligament length change using similar methods reported the ACL elongated more than $30 \%$ from $120^{\circ}$ to $0^{\circ}$ of flexion [14]. Hence, it was thought that the data in the current study was appropriate.

The PCL extended with flexion in the present study. Previous studies that investigated in vivo length change of the PCL using static methods also indicated the same pattern, including the absolute values [4, 34, 35]. This fact suggested that the PCL is commonly affected in high flexion, and the length change during dynamic motion was similar to that during static motion.

Regarding the MCL, adMCL, MdMCL, and asMCL extended from early flexion to mid-flexion. This trend was similar to previous studies [8, 10]. These facts suggested that the anterior portion of the MCL is easily affected in mid-flexion. Furthermore, the deep layer of the MCL might be easily affected in mid-flexion, because two thirds of the portion extended. During TKA for varus knee, we usually release the MCL to modify the soft tissue balance. Releasing the anterior and deeper layers of the MCL might be effective to modify midflexion balance.

Regarding the LCL, the anterior portion extended with flexion. This trend was similar to the previous study [10]. These facts suggested that the anterior portion could be affected in the lateral soft tissue balance, especially in high flexion. The high SD might mean high variation. Therefore, it might be impossible to detect the difference statistically because of the high variation. While this suggested that there is a high variation of LCL length change regardless of the type of high flexion activities in normal knees.

The high SDs in this study suggested many intersubject variations in normal knees. However, the trends were similar to previous studies $[8,10,36]$. Therefore, it is thought that the results of this study were appropriate.

Several limitations of this study need to be discussed. First, the present study only analyzed Japanese male subjects. Female subjects or other races might display different length changes. Second, the number of volunteers involved was small. Therefore, the present results might not be generalizable to the general population. Third, only normal knees were evaluated. The length changes to ligaments of osteoarthritis knees and knees after TKA might be different from those of normal knees. Therefore, we will investigate the length changes to ligaments of their knees in our next study. Forth, single bundles of ACL and PCL were analyzed in the current study. Double bundles analysis might show different results. Fifth, the length of the direct line between 
the attachment areas was defined as the ligament length in this study. While, some studies used shortest threedimensional wrapping path because the MCL wraps along the surfaces of the tibia and femur $[8,10]$. Therefore, the ligament length of MCL might be shorter than that of the previous studies $[8,10]$. However, a previous computer simulation study that used the straight line for ligament reported the ligament force was similar to the real ligament [37]. In addition, the ligament length change during squatting was similar to the previous studies $[8,10]$. Therefore, it is thought that the length change of MCL in this study is appropriate. Sixth, although each volunteer practiced several times before the fluoroscopic analysis, the kinematics was measured only one time per activity due to the radiation dose limit. An intra-subject variation may also affect the results.

\section{Conclusions}

The ACL was shorter during cross-leg motion than during squatting in mid-flexion. This suggests that the ACL is looser during cross-leg motion than during squatting. On the other hand, the length changes of the PCL, MCL, and LCL did not change even though the highflexion motions were different.

\section{Supplementary information}

Supplementary information accompanies this paper at https://doi.org/10. 1186/s12891-020-03560-3.

\section{Additional file 1.}

\section{Abbreviations}

TKA: Total knee Arthroplasty; ACL: Anterior cruciate ligament; PCL: Posterior cruciate ligament; dMCL: Deep medial collateral ligament; $\mathrm{SMCL}$ : Superficial medial collateral ligament; 2D/3D: 2-dimensional/3-dimensional; CAD: Computer-aided design; CT: Computed tomography; LCL: Lateral collateral ligament; MRI: Magnetic resonance imaging; a: Anterior; m: Middle; p: Posterior; L: Ligament length; L ref.: Reference ligament length; SD: Standard deviations; ANOVA: Analysis of variance

\section{Acknowledgements}

Not applicable.

\section{Authors' contributions}

$K K, T T$, and SK designed the study and the initial draft of the manuscript. KK, $\pi$, SK, and TY contributed to analysis of the kinematic data. ST and KS contributed to analysis a data and manuscript preparation. All other authors have contributed to data collection and interpretation, and critically reviewed the manuscript. The final version of the manuscript was approved by all authors.

\section{Funding}

This study was not supported by any funding.

\section{Availability of data and materials}

The datasets analysed during the current study are available from the corresponding author on reasonable request.

\section{Ethics approval and consent to participate}

This study was approved by Osaka University ethics committee (Number 13106). All of the volunteers in this study provided written, informed consent prior to participation.

\section{Consent for publication}

Not Applicable.

\section{Competing interests}

The authors declare that they have no competing interests.

\section{Author details}

'Department of Orthopaedic Surgery, Faculty of Medicine, The University of Tokyo, 7-3-1 Hongo, Bunkyo-ku, Tokyo 113-0033, Japan. ²Department of Orthopaedic Biomaterial Science, Osaka University Graduate School of Medicine, 2-2 Yamada-oka, Suita, Osaka 565-0871, Japan. ${ }^{3}$ Deapartment of Information Systems, Faculty of Engineering, Saitama Institute of Technology, 1690 Fusaiji, Fukaya, Saitama 369-0293, Japan.

Received: 3 May 2020 Accepted: 3 August 2020

Published online: 15 August 2020

\section{References}

1. Fleming BC, Beynnon BD, Tohyama H, Johnson RJ, Nichols CE, Renstrom $\mathrm{P}$, Pope $\mathrm{MH}$. Determination of a zero strain reference for the anteromedial band of the anterior cruciate ligament. J Orthopaedic Res. 1994;12(6):789-95.

2. Beynnon B, Howe JG, Pope MH, Johnson RJ, Fleming BC. The measurement of anterior cruciate ligament strain in vivo. Int Orthop. 1992;16(1):1-12.

3. Heijne A, Fleming BC, Renstrom PA, Peura GD, Beynnon BD, Werner S. Strain on the anterior cruciate ligament during closed kinetic chain exercises. Med Sci Sports Exerc. 2004;36(6):935-41.

4. Nakagawa S, Johal P, Pinskerova V, Komatsu T, Sosna A, Williams A, Freeman MA. The posterior cruciate ligament during flexion of the normal knee. J Bone Joint Surg Brit Vol. 2004;86(3):450-6.

5. Arms S, Boyle J, Johnson R, Pope M. Strain measurement in the medial collateral ligament of the human knee: an autopsy study. J Biomech. 1983; 16(7):491-6.

6. Hull ML, Berns GS, Varma H, Patterson HA. Strain in the medial collateral ligament of the human knee under single and combined loads. J Biomech. 1996;29(2):199-206.

7. Harfe DT, Chuinard CR, Espinoza LM, Thomas KA, Solomonow M. Elongation patterns of the collateral ligaments of the human knee. Clin Biomechanics (Bristol, Avon). 1998:13(3):163-75.

8. Park SE, DeFrate LE, Suggs JF, Gill TJ, Rubash HE, Li G. Erratum to "the change in length of the medial and lateral collateral ligaments during in vivo knee flexion". Knee. 2006;13(1):77-82.

9. Liu F, Gadikota HR, Kozanek M, Hosseini A, Yue B, Gill TJ, Rubash HE, Li G. In vivo length patterns of the medial collateral ligament during the stance phase of gait. Knee Surg Sports Traumatol Arthroscopy. 2011;19(5):719-27.

10. Hosseini A, Qi W, Tsai TY, Liu Y, Rubash H, Li G. In vivo length change patterns of the medial and lateral collateral ligaments along the flexion path of the knee. Knee Surg Sports Traumatol Arthroscopy. 2015;23(10): 3055-61.

11. Fleming BC, Renstrom PA, Beynnon BD, Engstrom B, Peura GD, Badger GJ, Johnson RJ. The effect of weightbearing and external loading on anterior cruciate ligament strain. J Biomech. 2001;34(2):163-70.

12. Taylor KA, Cutcliffe HC, Queen RM, Utturkar GM, Spritzer CE, Garrett WE, DeFrate LE. In vivo measurement of $\mathrm{ACL}$ length and relative strain during walking. J Biomech. 2013;46(3):478-83.

13. Kernkamp WA, Van de Velde SK, Hosseini A, Tsai TY, Li JS, van Arkel ERA, Li G. In vivo anterolateral ligament length change in the healthy knee during functional activities-a combined magnetic resonance and dual fluoroscopic imaging analysis. Arthroscopy. 2017;33(1):133-9.

14. Rao Z, Zhou C, Kernkamp WA, Foster TE, Bedair HS, Li G: In vivo kinematics and ligamentous function of the knee during weight-bearing flexion: an investigation on mid-range flexion of the knee. Knee Surgery, Sports Traumatol Arthroscopy 2019;28(3):797-805.

15. Moro-oka TA, Hamai S, Miura H, Shimoto T, Higaki H, Fregly BJ, Iwamoto Y, Banks SA. Dynamic activity dependence of in vivo normal knee kinematics. J Orthopaedic Res. 2008;26(4):428-34. 
16. Hemmerich A, Brown H, Smith S, Marthandam SS, Wyss UP. Hip, knee, and ankle kinematics of high range of motion activities of daily living. J Orthopaedic Res. 2006;24(4):770-81.

17. Acker SM, Cockburn RA, Krevolin J, Li RM, Tarabichi S, Wyss UP. Knee kinematics of high-flexion activities of daily living performed by male Muslims in the Middle East. J Arthroplast. 2011;26(2):319-27.

18. Bae DK, Song SJ, Cho SD. Clinical outcome of total knee arthroplasty with medial pivot prosthesis a comparative study between the cruciate retaining and sacrificing. J Arthroplast. 2011;26(5):693-8.

19. Nishio Y, Onodera T, Kasahara Y, Takahashi D, Iwasaki N, Majima T. Intraoperative medial pivot affects deep knee flexion angle and patientreported outcomes after total knee arthroplasty. J Arthroplast. 2014;29(4):702-6.

20. Yamazaki T, Watanabe T, Nakajima Y, Sugamoto K, Tomita T, Maeda D, Sahara W, Yoshikawa H, Tamura S. Visualization of femorotibial contact in total knee arthroplasty using X-ray fluoroscopy. Eur J Radiol. 2005;53(1):84-9.

21. Yamazaki T, Watanabe T, Nakajima Y, Sugamoto K, Tomita T, Yoshikawa H, Tamura S. Improvement of depth position in 2-D/3-D registration of knee implants using single-plane fluoroscopy. IEEE Trans Med Imaging. 2004; 23(5):602-12.

22. Kono K, Tomita T, Futai K, Yamazaki T, Tanaka S, Yoshikawa H, Sugamoto K. In vivo three-dimensional kinematics of normal knees during different highflexion activities. Bone Joint J. 2018;100-b(1):50-5.

23. Warren LF, Marshall JL. The supporting structures and layers on the medial side of the knee: an anatomical analysis. J Bone Joint Surg Am. 1979;61(1): 56-62.

24. LaPrade RF, Engebretsen AH, Ly TV, Johansen S, Wentorf FA, Engebretsen L. The anatomy of the medial part of the knee. J Bone Joint Surg Am. 2007; 89(9):2000-10.

25. Liu F, Yue B, Gadikota HR, Kozanek M, Liu W, Gill TJ, Rubash HE, Li G Morphology of the medial collateral ligament of the knee. J Orthop Surg Res. 2010;5:69.

26. Takeda S, Tajima G, Fujino K, Yan J, Kamei Y, Maruyama M, Kikuchi S, Doita M. Morphology of the femoral insertion of the lateral collateral ligament and popliteus tendon. Knee Surg Sports Traumatol Arthroscopy. 2015;23(10): 3049-54.

27. Takahashi H, Tajima G, Kikuchi S, Yan J, Kamei Y, Maruyama M, Sugawara A, Saigo T, Doita M: Morphology of the fibular insertion of the posterolateral corner and biceps femoris tendon. Knee Surg Sports Traumatol Arthroscopy 2016;25(1):184-91.

28. Shino K, Mae T, Tachibana Y. Anatomic ACL reconstruction: rectangular tunnel/bone-patellar tendon-bone or triple-bundle/semitendinosus tendon grafting. J Orthopaedic Sci. 2015;20(3):457-68.

29. Anderson CJ, Ziegler CG, Wijdicks CA, Engebretsen L, LaPrade RF. Arthroscopically pertinent anatomy of the anterolateral and posteromedial bundles of the posterior cruciate ligament. J Bone Joint Surg Am. 2012; 94(21):1936-45.

30. Tajima G, Nozaki M, Iriuchishima T, Ingham SJ, Shen W, Smolinski P, Fu FH. Morphology of the tibial insertion of the posterior cruciate ligament. J Bone Joint Surg Am. 2009;91(4):859-66.

31. Lee YS, Seon JK, Shin VI, Kim GH, Jeon M. Anatomical evaluation of CT-MRI combined femoral model. Biomed Eng Online. 2008;7:6.

32. Bates NA, Nesbitt RJ, Shearn JT, Myer GD, Hewett TE. Knee abduction affects greater magnitude of change in $\mathrm{ACL}$ and $\mathrm{MCL}$ strains than matched internal Tibial rotation in vitro. Clin Orthop Relat Res. 2017;475(10):2385-96.

33. Henning CE, Lynch MA, Glick KR Jr. An in vivo strain gage study of elongation of the anterior cruciate ligament. Am J Sports Med. 1985; 13(1):22-6.

34. DeFrate $L E$, Gill TJ, Li G. In vivo function of the posterior cruciate ligament during weightbearing knee flexion. Am J Sports Med. 2004;32(8):1923-8.

35. Papannagari R, DeFrate LE, Nha KW, Moses JM, Moussa M, Gill TJ, Li G. Function of posterior cruciate ligament bundles during in vivo knee flexion. Am J Sports Med. 2007;35(9):1507-12.

36. Li G, DeFrate LE, Sun $H$, Gill TJ. In vivo elongation of the anterior cruciate ligament and posterior cruciate ligament during knee flexion. Am J Sports Med. 2004;32(6):1415-20

37. Pandy MG, Sasaki K, Kim S. A three-dimensional musculoskeletal model of the human knee joint. Part 1: theoretical construct. Computer Methods Biomechanics Biomed Eng. 1998; (2):87-108

\section{Publisher's Note}

Springer Nature remains neutral with regard to jurisdictional claims in published maps and institutional affiliations.

Ready to submit your research? Choose BMC and benefit from:

- fast, convenient online submission

- thorough peer review by experienced researchers in your field

- rapid publication on acceptance

- support for research data, including large and complex data types

- gold Open Access which fosters wider collaboration and increased citations

- maximum visibility for your research: over $100 \mathrm{M}$ website views per year

At BMC, research is always in progress.

Learn more biomedcentral.com/submissions 